\title{
Aspectos da categorização de nome e verbo em libras
}

\author{
Name and verb category aspects in libras
}

\section{Aspectos de la clasificación del nombre y el verbo en libras}

\author{
iD Ediélia Lavras dos Santos Santana \\ Universidade Estadual do Sudoeste da Bahia (UESB), Cadeias, Bahia, Brasil. \\ E-mail: edielialavras@hotmail.com \\ iD Adriana Stella Cardoso Lessa-de-Oliveira \\ Universidade Estadual do Sudoeste da Bahia (UESB), Cadeias, Bahia, Brasil. \\ E-mail: adriana.lessa@uesb.edu.br
}

\begin{abstract}
Resumo: Objetivando caracterizar nome e verbo em Libras, fundamentados na Teoria Gerativa e em proposta de estrutura articulatória do sinal (LESSA-DE-OLIVEIRA, 2012, 2019), investigamos essas categorias, hipotetizando que, em Libras, marcam-se nomes e verbos apenas sintaticamente. Analisamos corpus experimental, utilizando, para transcrição e observação morfofonológica, o sistema de escrita de Libras SEL. Os resultados indicam que, em Libras, os sinais em posições nominais ou verbais são morfofonologicamente idênticos. Observamos certas variações fonológicas entre sinais, que não implicam categorização, as quais analisamos como decorrentes de aspecto estilístico ou semântico-pragmático. Concluímos que a categorização nessa língua não é definida morfofonologicamente, mas pela sintaxe.
\end{abstract}

Palavras-chave: Contexto Sintático. Libras. Nome. Verbo.

Abstract: Aiming to characterize name and verb in Libras, based on the Generative Theory and proposal of the articulatory structure of the sign (LESSA-DE-OLIVEIRA, 2012, 2019), we investigated these categories 
by hypothesizing that in Libras only names and verbs are marked syntactically. We analyzed experimental corpus using, for transcription and morphophonological observation, the Libras writing system SEL'. The results show that, in Libras, the signs in nominal or verbal positions are morphophonologically identical. We observed certain phonological variations between signals, which do not imply categorization, which we analyzed as arising from stylistic or pragmatic semantic aspects. We conclude that categorization in this language is not defined morphophonologically, but by syntax.

Keywords: Syntactic Context. Pounds. Name. Verb.

Resumen: Con el objetivo de caracterizar el nombre y el verbo en Libras, en base a la Teoría Generativa y a la propuesta de la estructura articulatoria del signo (LESSA-DE-OLIVEIRA, 2012, 2019), investigamos esas categorías, hipotetizando que, en Libras, los nombres y los verbos están marcados sólo sintácticamente. Analizamos el corpus experimental, utilizando para la transcripción y observación morfofonológica el sistema de escritura de Libras SEL. Los resultados indican que, en Libras, los signos en posiciones nominales o verbales son morfofonológicamente idénticos. Entre las señales, observamos ciertas variaciones fonológicas que no incluyen una clasificación, las cuales analizamos como provenientes del aspecto estilístico o semántico-pragmático. Concluimos que la clasificación en esta lengua no se define morfofonológicamente, sino a través de la sintaxis.

Palabras clave: Contexto Sintáctico. Libras. Nombre. Verbo.

Submetido em 24 de outubro de 2019.

Aceito em 19 de maio de 2020.

Publicado em 24 de março de 2021

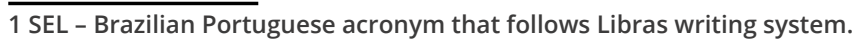




\section{Introdução}

A observação e identificação de categorias gramaticais e suas características, como nomes, verbos, adjetivos, advérbios, preposições etc., em estudos que abordam uma Língua oral (LO), se dá, comumente, sem maiores intempéries devido à ocorrência, muito comum nessas línguas, de morfologia categorial explícita, marcando propriedades categoriais como gênero, número, tempo, pessoa etc. Entretanto, tal facilidade na identificação e delimitação de categorias gramaticais não ocorre no caso da Libras. Geralmente, em línguas sinalizadas, não se observa, a priori, nenhuma modificação morfofonológica nos sinais, quando estes ocupam uma posição nominal, verbal, adjetival ou adverbial na frase. Não obstante, autores como Quadros e Karnopp (2004) assumem a existência de uma morfologia explícita, definidora das categorias nome e verbo em Libras.

Considerando tal problema, propomo-nos a investigar ${ }^{2}$ como, em Libras, as categorias dos verbos e nomes (doravante $\mathrm{N}$ e V) se definem, trazendo ou não marcas articulatórias que correspondam a morfemas categorizadores. Assumindo a Teoria Gerativa Minimalista, estamos obviamente considerando que a categorização do item lexical, o sinal, no caso da Libras, diz respeito a traços abstratos correspondentes a propriedades formais específicas das categorias gramaticais. Assim, é importante ressaltar que a não manifestação de uma morfologia explícita, que caracterize categorialmente os sinais em Libras, não significa dizer que os traços abstratos, que rotineiramente se manifestam como morfemas funcionais nas LO, não estejam presentes nas línguas de sinais (LS).

Propusemo-nos, neste estudo, analisar 25 pares de $\mathrm{N}$ e V, investigados por Pizzio (2011), comparando a produção de três grupos de informantes, a saber: surdos com aquisição da Libras na infância (SALI), surdos com aquisição da Libras pós-infância (SALPI) e ouvintes falantes fluentes de Libras (OFL). Acrescentamos ao

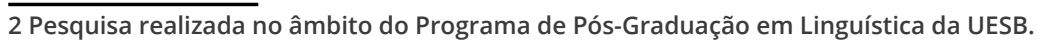


experimento elementos de análise sintática e transcrição que pudessem agregar critérios para identificação de $\mathrm{N}$ e $\mathrm{V}$ e possíveis diferenças morfossintáticas existentes ou não nos dados da Libras coletados via testes. No quadro a seguir, temos os 25 pares de $\mathrm{N}$ e $\mathrm{V}$ utilizados no teste.

\section{Quadro 1: Pares de verbo e nome utilizados no teste}

\begin{tabular}{|c|c|}
\hline BICICLET[ar] & BICICLET[a] \\
\hline $\mathrm{ABR}[\mathrm{ir}]_{\text {PORTA }}$ & PORTA \\
\hline TESOUR[ar] & TESOUR[a] \\
\hline PENT[ear] & PENT[e] \\
\hline CORR[er] & CORR[ida] \\
\hline NEV[ar] & NEV[e] \\
\hline CHOV[er] & CHUV[a] \\
\hline PENS[ar] & PENS[amento] \\
\hline SONH[ar] & SONH[O] \\
\hline CHUT[ar] & FUTEBOL \\
\hline ROUB[ar] & LADR[ão] \\
\hline EXPLOD[ir] & EXPLOS[ão] \\
\hline NAD[ar] & NAT[ação] \\
\hline CONSTRU[ir] & CONSTRU[ção] \\
\hline BRINC[ar] & BRINQU[edo] \\
\hline BEB[er] & BEB[ida] \\
\hline COM[er] & COM[ida] \\
\hline SENT[ar] & CADEIRA \\
\hline VENT[ar] & VENT[O] \\
\hline TELEFON[ar] & TELEFON[e] \\
\hline DIRIG $[\text { ir }]_{\text {CARRO }}$ & CARRO \\
\hline PASS[ar] $]_{\text {ROUPA }}$ & FERRO \\
\hline CHOR[ar] & CHOR[O] \\
\hline SORR[ir] & SORR[iso] \\
\hline CAS[ar] & CAS[amento] \\
\hline
\end{tabular}

Fonte: Das autoras (2019)

Assim, constituímos o corpus da pesquisa a partir de um teste de eliciação por meio de imagens das quais fosse possível ex- 
trair frases contendo os pares $\mathrm{N}$ e $\mathrm{V}$ acima. Procuramos provocar a ocorrência de $\mathrm{N}$ e $\mathrm{V}$, como no exemplo abaixo, em que, para eliciar o verbo PASS[ar]ROUPA, escolhemos uma imagem de uma mulher passando uma pilha de roupas. Já para eliciar o nome FERRO, escolhemos uma imagem com o ferro totalmente destituído de sua função de passar roupa. Selecionamos, para isso, uma imagem de um ferro sendo usado para fritar linguiça.

\section{Figura 1: Imagens usadas no teste para eliciar os sinais FERRO/PASSARROUPA}

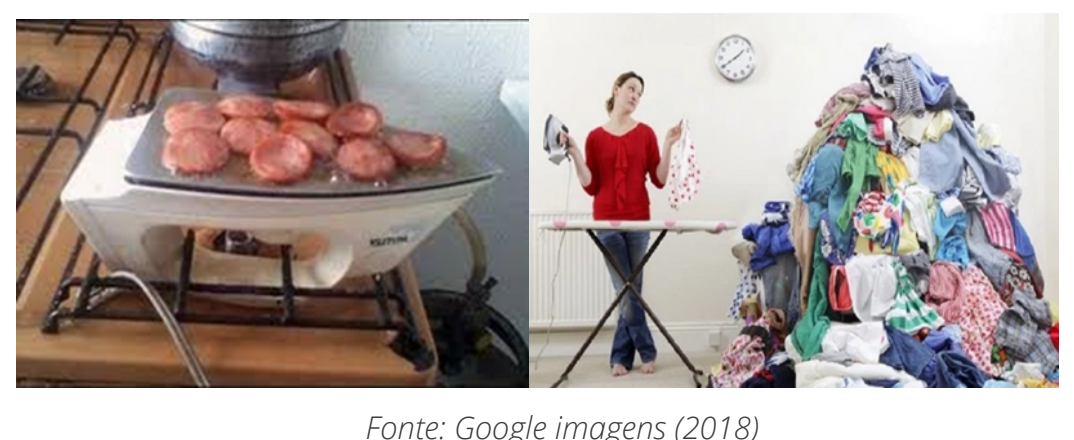

Para transcrição dos dados, utilizamos o sistema SEL - Sistema de Escrita de Libras, desenvolvido por Lessa-de-Oliveira (2012; 2019). Utilizamos esse sistema na transcrição dos dados, por ele permitir que os sinais sejam preservados em suas características articulatórias com enorme precisão, tal como foram realizados pelos informantes, o que é imprescindível a essa pesquisa, que se propôs a analisar a produção dos falantes ao sinalizar pares de $\mathrm{Ne}$ $V$, na tentativa de identificar algum morfema categorizador foneticamente realizado. Utilizamos também glosas e interpretação em Português para facilitar a compreensão dos dados pelos leitores de modo geral.

Assumimos a Teoria Gerativa na caracterização morfossintática das categorias da Libras estudadas, além da proposta de Lessa-de-Oliveira (2012) para a estrutura articulatória do sinal. Essa proposta nos forneceu visão sobre uma série de traços e segmentos articulatórios que podem atuar na formação de um paradigma 
morfossintático de marcação das propriedades formais das categorias $\mathrm{N}$ e $\mathrm{V}$ em Libras.

\section{Pressupostos gerativistas para aquisição da linguagem e a Gramática Gerativa}

\subsection{A Libras como língua internalizada}

Para investigar como se dá a categorização de $\mathrm{N}$ e V em Libras, tomando-a como uma língua natural, devemos dispor de uma teoria que conceba a língua como faculdade natural à espécie humana, tal como faz a Teoria Gerativa, de acordo com a qual todo ser humano, ao nascer, é dotado de uma faculdade da linguagem, uma capacidade inata para a linguagem, denominada Gramática Universal (doravante GU). Para Chomsky (1998), as propriedades desse órgão são representações mentais. Assumindo essa teoria, compreendemos que, como língua natural, a Libras se assenta na GU, constituída de princípios universais e rígidos e parâmetros, variáveis, flexíveis. Inicialmente, os parâmetros das línguas apresentam-se abertos a uma marcação positiva ou negativa no momento da aquisição da linguagem, quando a criança é exposta aos estímulos linguísticos, também conhecidos como input linguístico.

No que concerne aos estágios de aquisição da linguagem, quer seja por ouvintes ou surdos, uma questão que se coloca diz respeito ao período considerado ideal para esse processo, comumente conhecido como "período crítico ou sensível". Conforme propôs Lenneberg (1967), esse período se delimita aproximadamente entre 0 e 6 anos de idade e corresponde à fase propícia para a aquisição da linguagem, devendo haver uma exposição suficiente à língua nesse período para que esta seja adquirida como língua nativa.

Partindo dessa proposição, o processo de aquisição da linguagem fora do período crítico é considerado aquisição tardia. Considera-se que a criança que, por algum motivo, seja privada de input da língua em aquisição, durante o período sensível, não poderá 
adquirir essa língua como nativa, e o processo de aquisição que vier a ocorrer posteriormente a esse período pode apresentar marcas de aquisição não nativa, isto é, que estaria sujeita a certas "imperfeições" gramaticais.

Essa questão traz muitas perguntas a respeito do processo de aquisição de línguas de sinais por surdos, pois a realidade, bem comum no Brasil e em outros países, é que os surdos, em geral, não têm acesso a uma língua de sinais assim que nascem, ficando a maioria dessas pessoas à mercê de uma aquisição tardia de uma LS. No caso do Brasil, por exemplo, a maior parte dos surdos são filhos de famílias ouvintes, não falantes de Libras, tendo esses surdos, por isso, seu contato inicial com a Libras em idade avançada, quando são inseridos no contexto escolar, muitas vezes por meio de um ouvinte que também está aprendendo a língua como L2. Diante de um ambiente tão desfavorável a uma aquisição natural da língua, resta-nos perguntar se a Libras falada pela maioria dos brasileiros surdos tem um caráter de língua nativa ou não, frente à comparação com a Libras falada por surdos que conviveram desde o nascimento com pais surdos? Não nos dedicamos, neste estudo, a buscar resposta a essa pergunta, uma vez que essa não remete diretamente ao nosso objeto. Entretanto, por não poder deixar de considerar esse aspecto, procuramos abarcar a variável 'idade de aquisição da Libras', juntamente com a variável 'ser ouvinte ou surdo', na constituição dos nossos grupos de informantes, com o objetivo de verificar se esse fator apresentava alguma diferença nos resultados dos testes aplicados.

No que tange à aquisição da Libras com L2 (segunda língua) por ouvintes, assumimos a hipótese de acesso indireto à GU, por entender, em conformidade com Kato (2005), que essa proposta explica mais satisfatoriamente a interferência da L1 (primeira língua) na L2. Dessa forma, estamos considerando que os nossos informantes ouvintes são falantes que adquiriram, e não apenas aprenderam, a Libras. Chamamos a atenção para o fato de que os nossos informantes do grupo de ouvintes tiveram processo de aquisição por imersão. Sendo assim, essa aquisição se deu de 
forma inconsciente, no que diz respeito à fixação de valores paramétricos propriamente ditos, não obstante haja algum nível de consciência pelo menos em aspectos superficiais, como busca de itens lexicais novos.

\subsection{Postulações gerativistas para nome e verbo}

De acordo com a Teoria Gerativa, em sua versão minimalista, os itens lexicais são formados de traços abstratos de três tipos: semânticos, fonológicos e formais. Esses últimos são os que definem a categoria gramatical do item lexical dentro da frase. Sobre os traços que derivam $\mathrm{N}$ e $\mathrm{V}$, esses se apresentam da seguinte forma, nas palavras de Mioto (2016):

[...] tomemos um radical com am- do qual se derivam um nome amor, um adjetivo amado e um verbo amar. O radical em si se presta a estabelecer o sentido lexical da palavra (a famosa relação de amor) e a princípio não é associado a ele qualquer traço $[ \pm \mathrm{V}]$ ou $[ \pm \mathrm{N}]$. Desse radical pode ser formada a palavra amar que é definida pelos traços $[-\mathrm{N},+\mathrm{V}]$ e identificada como um verbo: não tem traços [+N] como gênero e tem traços [+V] reconhecidos como morfemas verbais como tempo, modo e/ ou aspecto. A palavra amor é definida pelos traços $[+\mathrm{N},-\mathrm{V}]$ e é identificada como um nome: tem traços $[+N]$ de gênero e não tem traços [+V]. E a palavra amado? Sem dúvida pode ter traços [+N] de gênero e número quando é combinada com o verbo ser (Maria foi amada por João), por exemplo, não porta tais traços quando combinado com o verbo ter (A Maria tinha amado João), caso em que revela o aspecto verbal. Por isso, a palavra, amado é definida pelos traços [+N,+V]. (p. 57)

Vemos que, em línguas naturais como o Português, pode ocorrer, parametricamente, a manifestação morfofonológica de 
traços associados à categoria gramatical do item lexical. Entretanto, sabemos que essa não é a única forma de manifestação/estabelecimento da categorização lexical nas línguas naturais e talvez nem seja o fator mais importante. Dessa forma, havemos de considerar a relevância da posição sintática no estabelecimento da categoria lexical. Conforme a proposição gerativista, o sistema computacional forma a estrutura sintática a partir dos traços formais, semânticos e fonológicos contidos nos itens lexicais, mandando as informações sobre essa estrutura para as interfaces Forma Lógica, que se comunica com os sistemas de pensamento, e Forma Fonética, que se comunica com o sistema sensório motor, resultando na apresentação morfofonológica ou não peculiar a cada língua. Vejamos um exemplo do Português retirado de Kennedy (2016, p. 139).

(1) [sujeito João [predicado viu Maria]].

(2) *[sujeito João [predicado visão Maria]].

De acordo com Kenedy (2016), em (1), o item 'ver' informa ao sistema computacional que ele é um verbo, pois carrega os traços da categoria $V$, colocando-se em uma posição, na frase, em que somente um verbo pode estar. Sendo assim, a frase é licenciada, não causando nenhuma estranheza ao ser proferida. Já em (2), temos uma frase agramatical, pois nesta o item 'visão', um nome, está posicionado no lugar da categoria $\mathrm{V}(=[+\mathrm{V},-\mathrm{N}])$. Ou seja, uma vez que 'visão' é um nome, cujos traços categorias são $N\left(=\left[-V_{1}+N\right]\right)$, isto gera o não licenciamento da frase.

A partir dessa exemplificação, podemos nos perguntar qual é a natureza de traços categorizadores de $\mathrm{N}$ e V? Observamos no Português que, quanto aos traços categorizadores do verbo, esses definem tanto as flexões morfofonológicas, que marcam as propriedades de tempo, modo e aspecto, quanto às relações semânticas, definidas por papéis temáticos, e às relações formais, que são definidoras da posição sintática central do verbo no 
segmento oracional. Quando pronunciamos o verbo 'beber', por exemplo, são os traços fonológicos que estabelecem a relação da língua com nosso sistema articulatório-perceptual, o qual nos faz, por meio do aparelho sensório-motor, produzir os sons da fala. Nesse item, também estão contidas outras informações como, por exemplo, a ação de ingerir algo líquido, informações que estão nos traços semânticos. Por sua vez, os traços formais dizem respeito às relações que este verbo irá estabelecer com outros elementos em uma sentença. Sabemos que o verbo 'beber' irá estabelecer relações com um Agente (quem bebe), que é o papel temático do argumento externo desse verbo, e um Tema ou o objeto do processo (o que é bebido), que é seu argumento interno.

(3) [Agente Carlos] bebeu [Tema o suco].

Já os traços categorizadores do nome definem: as flexões morfológicas, que marcam as propriedades de gênero e número; as relações semânticas, por via de papéis temáticos recebidos, quando os nomes estão na posição de argumentos selecionados por outro núcleo lexical predicador, ou por via de papéis temáticos atribuídos, quando esses estão na posição de predicadores; e as relações formais, que são definidoras da posição sintática por meio do sistema de Casos.

E numa língua como a Libras, como se manifestam os traços relacionados à categorização de $\mathrm{N}$ e V? Vemos, com base na observação do Português, que temos dois ambientes de investigação: o contexto morfológico e o sintático. No caso do contexto morfológico, temos aí associado aspectos fonológicos. Nas próximas seções, traremos discussões de aspectos da Libras relacionados a esses três módulos gramaticais.

\section{A estrutura articulatória do sinal na Língua Brasileira de Sinais}

O pioneirismo em investigar a natureza articulatória do sinal na ASL cabe ao linguista estadunidense William Stokoe (1960). 
Esse linguista propôs uma estrutura formada por componentes articulatórios que ele denominou 'parâmetros'3. Seus achados se estenderam a estudos sobre línguas de sinais no mundo inteiro, incluindo a Libras, levando os pesquisadores, de modo geral, a propor análises das diversas línguas sinalizadas com base nesses parâmetros. Assim, seguindo a análise e a terminologia de Stokoe, no sistema fonológico da Libras, teríamos cinco parâmetros, que são: Configuração de mão, Locação, Movimento, Orientação e Expressões faciais.

Concebendo a estrutura articulatória do sinal de forma semelhante aos itens lexicais de outras línguas naturais, Lessa-de-Oliveira $(2012,2019)$ defende que esses parâmetros são apenas traços que formam segmentos superiores de três tipos distintos. ${ }^{4}$ Ou seja, diferentemente das análises já feitas, as quais colocam os segmentos articulatórios, acima citados (os parâmetros), num mesmo nível, equiparando-os algumas vezes a fonemas, Lessa-de-Oliveira $(2012,2019)$ propõe que os sinais da Libras têm uma estrutura articulatória hierárquica em que esses elementos, os ditos parâmetros, são traços que constituem um primeiro nível articulatório de uma estrutura hierárquica composta por quatro níveis. Lessa-de-Oliveira (2012, 2019) juntou nesse primeiro nível os cinco segmentos acima citados e outros descobertos durante suas análises, são eles: três eixos de posição da mão, três planos de movimento, tipo de movimento de mão, movimento de dedo e ponto de toque. No segundo nível dessa estrutura, encontram-se o que a autora chama de macrossegmentos, que reúnem os traços do primeiro nível em três grupos, Mão (M), Locação (L) e Movimento (Mov.). No terceiro nível ocorrem as unidades formadas por esses macrossegmentos, constituindo assim a unidade MLMov; e, no quarto nível, reúnem-se as unidades MLMov, compondo o sinal. Na figura a seguir, encontra-se um resumo da proposta dessa autora para o que ela denomina de 'estrutura articulatória hierárquica do sinal'.

30 termo "parâmetro", utilizado por Stokoe, não se refere ao termo parâmetro empregado dentro dos estudos gerativistas. 4 Outra autora a assumir para a Libras uma estrutura articulatória em níveis hierárquicos é Marinho (2014). 
Figura 2: Estrutura Articulatória do Sinal, segundo Lessa-de-Oliveira

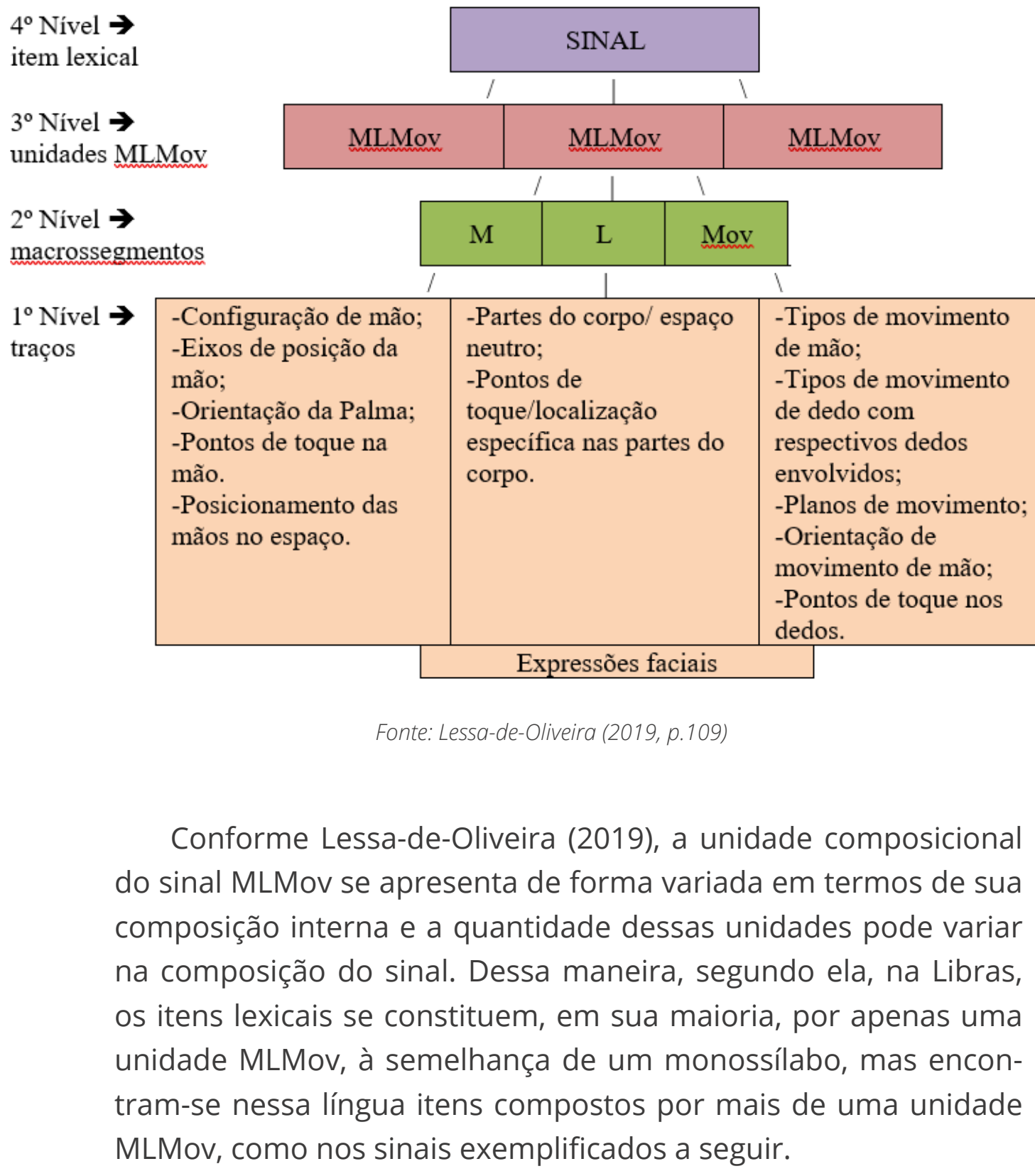


(4) a. CASA

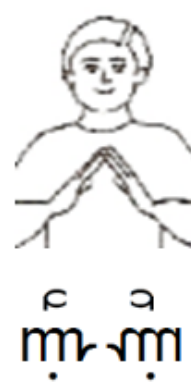

$[\mathrm{M}]$ b. ONÇA

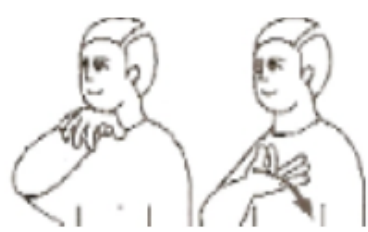

0

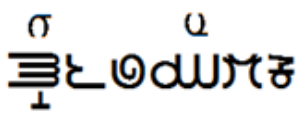

[MLMov][MLMov] c. MADRASTA

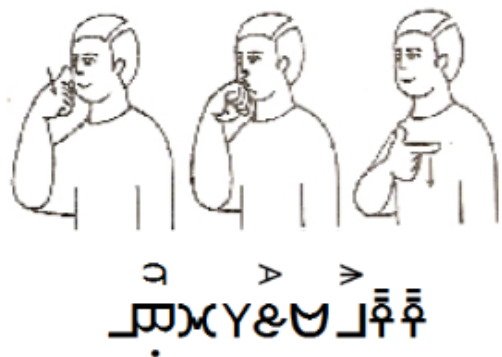

$[\mathrm{MLMov}][\mathrm{ML}][\mathrm{MMov}]$

(LESSA-DE-OLIVEIRA, 2019, p. 115)

Conforme a autora, podemos observar, nesses exemplos, que o sinal CASA em (4a) compõe-se de uma unidade que só apresenta o macrossegmento Mão [M], no qual ambas as mãos configuradas em mão espalmada (mr, rm), no eixo superior/palma para dentro $(c, a)$, tocam-se pelas pontas dos dedos (•). Já o sinal ONÇA, em (4b), apresenta duas unidades MLMov completas, isto é, com os

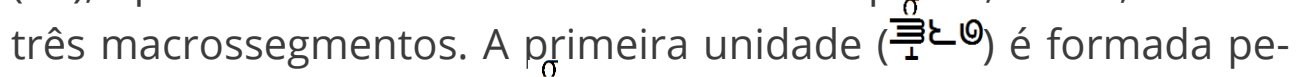
los macrossegmentos: $\mathbf{M}\left(\frac{\hat{\bar{B}}}{\overline{1}}\right)$, com os traços: mão configurada em garra (छ), no eixo medial/palma para baixo $(\sigma)$, com toque no dorso da mão(ı); L, com apenas o traço queixo-と; e Mov, com os traços movimento circular, no plano transversal (๑). E a segunda unidade

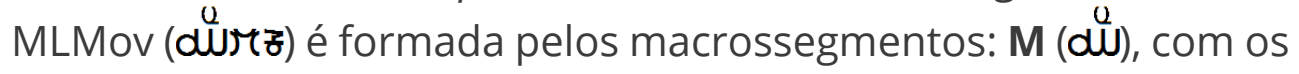
traços: mão configurada em argola espraiada (d)), no eixo medial/ palma para cima $\mathbf{Q}$; L, com apenas o traço tórax (T); e Mov, com os traços movimento zigue-zague e plano frontal (₹). Por fim, o sinal MADRASTA, em (4c), apresenta três unidades, sendo a primeira

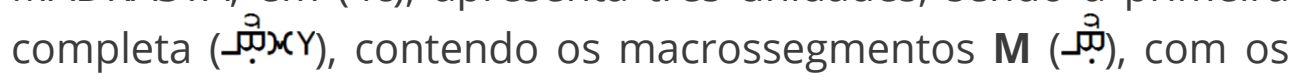
traços: mão configurada em legal $(\boldsymbol{\omega})$, no eixo superior/palma para dentro (a), com toque na ponta do dedo $(\bullet) ; \mathbf{L}$, com apenas o traço bochecha ( $)$; e Mov, com o traço movimento retilíneo para frente (Yfalse); a segunda unidade, constituída como ML ( (\&)), se forma pelos macrossegmentos: $\mathbf{M}(\vec{\varepsilon})$, com os traços: mão configurada em esse $\boldsymbol{\&}$, no eixo medial/palma para frente ( $>$ false) e $\mathbf{L}$, com apenas o traço boca $(\Theta)$; e a terceira unidade, constituída como MMov 
( $(\vec{\jmath} \overline{\bar{P}} \overline{\bar{q}})$, se forma pelos macrossegmentos: $\mathbf{M}(\overrightarrow{\lrcorner})$ ), com os traços: mão configurada em ele (\lrcorner$)$, no eixo medial/palma para trás $(\rightarrow)$; e Mov ( $\overline{\bar{q}} \overline{\bar{q}})$, com o traço retilíneo brevíssimo para cima $\overline{\overline{\hat{q}}}$, que se repete.

\section{Representação da estrutura articulatória do sinal pelo sistema SEL}

Conforme já mencionamos, a constituição morfológica do sinal é um dos aspectos indispensáveis à análise da categorização de $\mathrm{N}$ e $\mathrm{V}$ em Libras. Assim, torna-se imprescindível nesse tipo de análise a representação da estrutura articulatória do sinal da Libras, que serve para evidenciar a presença ou não de manifestação morfofonológica dos traços categoriais. Temos a possibilidade de fazer essa representação por meio do sistema de escrita para Libras SEL, desenvolvido por Lessa-de-Oliveira $(2012,2019)$. Então, vejamos um exemplo de como esse sistema representa a estrutura articulatória do sinal, através de caracteres e diacríticos que representam os traços, os macrossegmentos e as unidades MLMov:

Figura 3: Macrossegmentos da Unidade MLMov representados em SEL

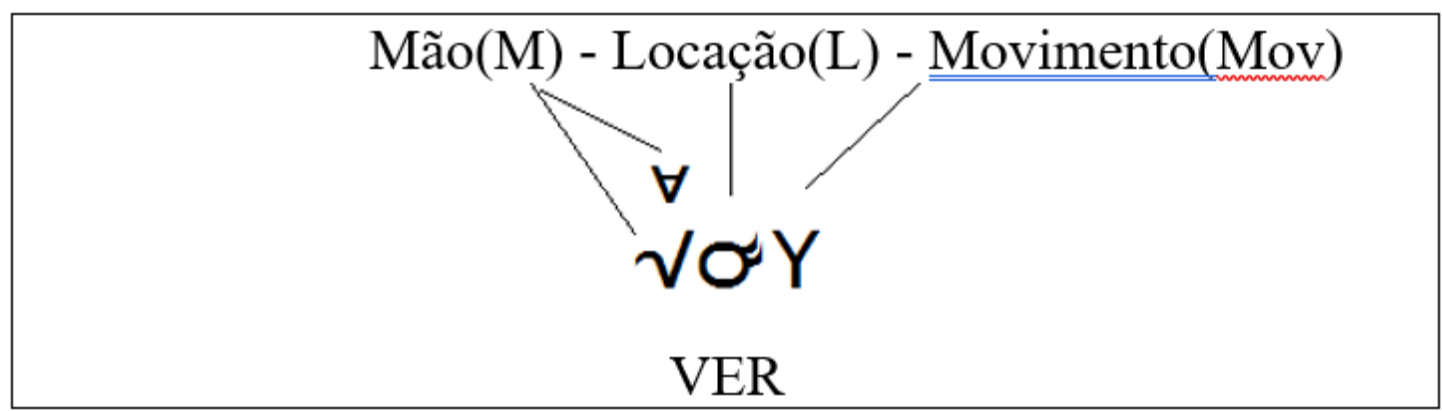

Fonte: Lessa-de-Oliveira, 2019 (Blog Escrita SEL http://sel-libras.blogspot.com.br)

Nesse exemplo, o Macrossegmento M se compõe dos seguintes traços: configuração de mão em vê, representada pelo carac- 
tere $\boldsymbol{V}$, eixo superior e orientação da palma para frente, representados de forma amalgamada pelo diacrítico $\forall$. O macrossegmento $L$, que se compõe nesse exemplo apenas pelo traço olho, representado pelo caractere $\sigma$. E o macrossegmento Mov apresenta os traços movimento de mão retilíneo e orientação para frente, traços representados de forma amalgamada pelo caractere $\mathbf{Y}$.

Conforme Lessa-de-Oliveira (2012), o sistema SEL apresenta 52 caracteres para representar os traços configurações de mão, 12 diacríticos para representar, de forma amalgamada, os traços eixo da mão e orientação de palma, que são colocados acima da configuração de mão $(\mathfrak{V})$. Esses diacríticos indicam a posição da mão nos eixos tridimensionais superior, anterior ou medial/lateral e a orientação da palma. Ou seja, a autora indica a existência de três eixos, com quatro orientações de palma em cada eixo.

Quanto ao macrossegmento Locação (L), a escrita SEL representa, com 20 caracteres e diacríticos de pontos de toque, um total de 32 pontos de articulação, que envolvem todas as partes e pontos do corpo que atuam nesse macrossegmento. Os diacríticos de pontos de proximidade/toque, representados no sistema SEL por 11 elementos, ocorrem no macrossegmento $M$, marcando o traço proximidade/toque em pontos da mão, no macrossegmentos $L$, marcando proximidade/toque em pontos das partes do corpo, e no macrossegmento Mov, em certos casos de movimento de dedos, marcando proximidade/toque em pontos dos dedos.

E o último macrossegmento, o de Movimento (Mov), é representado pelo sistema SEL, conforme suas características articulatórias, dividido em dois grupos: (A) movimento de mão, que é composto por três traços, representados de forma amalgamada no mesmo caractere, a saber: tipo (varia em 13 tipos: retilíneo, semicircular, curvo, angular duplo, angular, sinuoso, zigue-zague, diagonal, circular, giro de punho, dobrar punho, tremura e batida), plano (varia em 3 possibilidades: transversal, sagital e frontal) e orientação (varia em 6 possibilidades: para frente, para trás, para cima, para baixo, para direita, para esquerda) -; e (B) movimento de dedo, que é representado por um caractere de dedo ou dedos (varia em 
19 possibilidades de combinações de dedos envolvidos no movimento) e um diacrítico sobreposto indicando o tipo de movimento (varia em 11 possibilidades: abrir, abrir com repetição, abrir gradativamente, fechar, fechar com repetição, fechar gradativamente, abrir e fecha, movimento tesoura, zigue-zague, dobrar e esfregar).

Outro tipo de traço articulatório identificado por Lessa-de-Oliveira $(2012$; 2019) como componente da articulação de sinais é o de expressão facial, o qual é marcado na escrita SEL por diacríticos que ocorrem sobrescritos aos caracteres de Locação ou de Movimento, caso não ocorra caractere de Locação.

Além disso, o sistema SEL ainda possui, para os sinais realizados com duas mãos, diacríticos colocados entre os caracteres de configuração de mão, para marcar a posição de uma mão em relação à outra (mãos em paralelo, alinhadas, em diagonal ou cruzadas) e a simultaneidade/alternância dos movimentos de ambas as mãos. ${ }^{5}$ E a SEL apresenta também um diacrítico para marcar a intensificação do movimento.

A fim de verificar como a utilização da escrita SEL como recurso de transcrição dos dados foi importante para as análises realizadas neste estudo, observemos a amostra de dados a seguir, nas quais podemos verificar as variações articulatórias que ocorreram, ou não, na realização dos sinais investigados em posições verbais e nominais nas frases produzidas pelos sujeitos-informantes.

(5)

TELEFONAR / TELEFONE
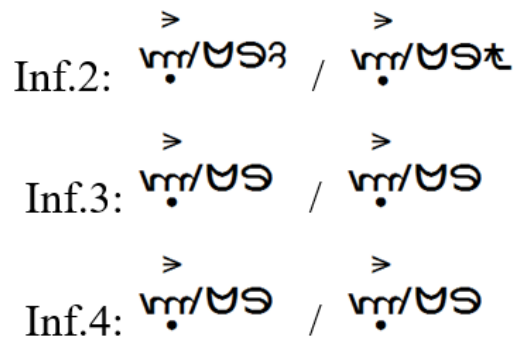

ROUBAR / LADRÃO

Inf.2:

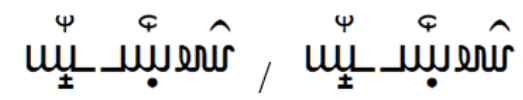

Inf.3:

$m_{ \pm}^{\infty} \stackrel{p}{p} \stackrel{\oplus}{=}=$

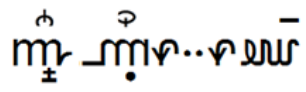

Inf.4:

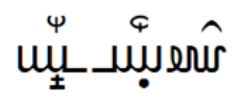

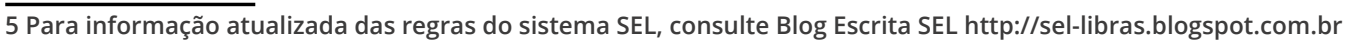


Para o par TELEFONAR / TELEFONE, verificamos nessa amostra que Inf.2 faz um movimento giro de punho para o verbo, representado em SEL pelo caractere 3 , e, para nome, um movimento curvo para trás no plano sagital, representado em SEL pelo caractere $九$, os quais os outros informantes não realizam. Já para o par ROUBAR / LADRÃO ocorre a mesma forma para o verbo e o nome nos dados de Inf.2 e para o verbo nos dados de Inf.4. Ocorre uma

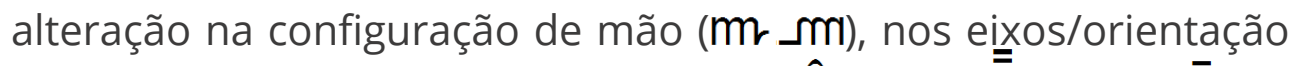

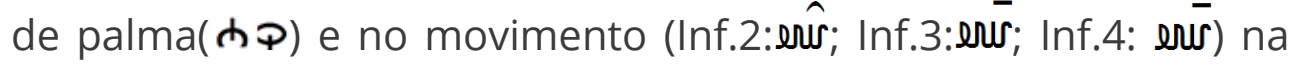
forma como Inf.3 e Inf.4 realizam o verbo em comparação com a realização de Inf.2; e Inf.3 acrescenta ao nome um movimento semicircular para trás no plano transversal $(\boldsymbol{\varphi})$, realizado conjuntamente entre as duas mãos (••).

Como vemos, a escrita SEL apresenta recurso para representar cada um desses traços articulatórios, por se tratar de um sistema de natureza trácico-fonêmica. Como foram coletadas e analisadas mais de mil frases, a observação minuciosa dos traços e a comparação exaustiva dos pares de sinais seriam impossível sem um recurso de transcrição como esse. A escrita SEL também se mostrou um recurso importante para a análise sintática dos dados, como será demonstrado na seção 6. Isto porque, para identificação da categoria gramatical do sinal pela via sintática, faz-se necessária a observação da frase sem interferência da estrutura sintática de outra língua, o que exige a observação dos dados articulados na própria língua investigada, algo praticamente impossível de ser alcançado analisando-se apenas glosas.

\section{Proposta de generalização morfofonológica para nome e verbo em Libras}

Ao analisar as LS, muitos partem do pressuposto da presença de contraste entre as categorias $\mathrm{N}$ e V, como se verifica comumente em LO como o Português, embora não haja pesquisas que tenham conseguido demonstrar claramente a natureza deste con- 
traste entre os sinais, ou mesmo a relevância de contraste morfológico dessas categorias lexicais nas LS. Alguns estudos sobre LS defendem como critério para a distinção entre $\mathrm{N}$ e $\mathrm{V}$ certo aspecto morfológico: variação no movimento. Ainda que esse tipo de distinção possa ter sido encontrado em alguma LS, não é fato que tal morfema categorizador possa ser generalizado no universo das LS, semelhantemente ao que ocorre com as LO, que também não apresentam morfologia categorial generalizada.

Quadros e Karnopp (2004) propõem, para nomes e verbos em Libras, os mesmos padrões encontrados na American Sing Language (ASL), em estudos como o de Supalla e Newport (1978), que indicam a existência de um contraste entre $\mathrm{N}$ e $\mathrm{V}$ marcado pelo tipo de movimento. O pressuposto, assumido pelas autoras acima, é de que esse critério se aplica às LS em geral. Quadros e Karnopp (2004) sugerem que nomes são oriundos de certos sinais relacionados a conceitos verbais, sendo o verbo, em Libras, caracterizado por um movimento longo, enquanto que no nome o movimento seria breve e repetitivo. As autoras concluem, assim, que:

Supalla e Newport observaram que pares de nomes e verbos diferem-se um do outro apenas no tipo de movimento do sinal. Tais conclusões aplicáveis às regras morfológicas da língua de sinais podem ser ilustradas com o par SENTAR e CADEIRA: a locação, a configuração e a orientação de mão dos dois sinais são as mesmas, mas o movimento é diferente. É o movimento que cria a diferença no significado entre os dois tipos de sinais. Neste sentido, a locação, a configuração e a orientação de mão dos sinais ROUBAR e LADRÃO são as mesmas, mas o movimento e diferente. (p. 100).

Conforme ilustram as figuras a seguir dos sinais da Libras, apresentadas pelas autoras, o sinal TELEFONAR se configura como $\checkmark$ porque tem os traços de movimento único e alongado, já o sinal TELEFONE se configura como $N$ porque seus traços são de movimento curto e reduplicado. Da mesma forma, o sinal CADEIRA se- 
ria um $\mathrm{N}$ porque é formado pelo movimento curto e reduplicado, enquanto seu par seria um V com movimento único e alongado; e o sinal PERFUME seria um N, com movimento curto e reduplicado, enquanto que seu par PERFUMAR seria um $V$, com movimento único e alongado. Vejamos:

\section{Figura 4: Mudança Categorial}

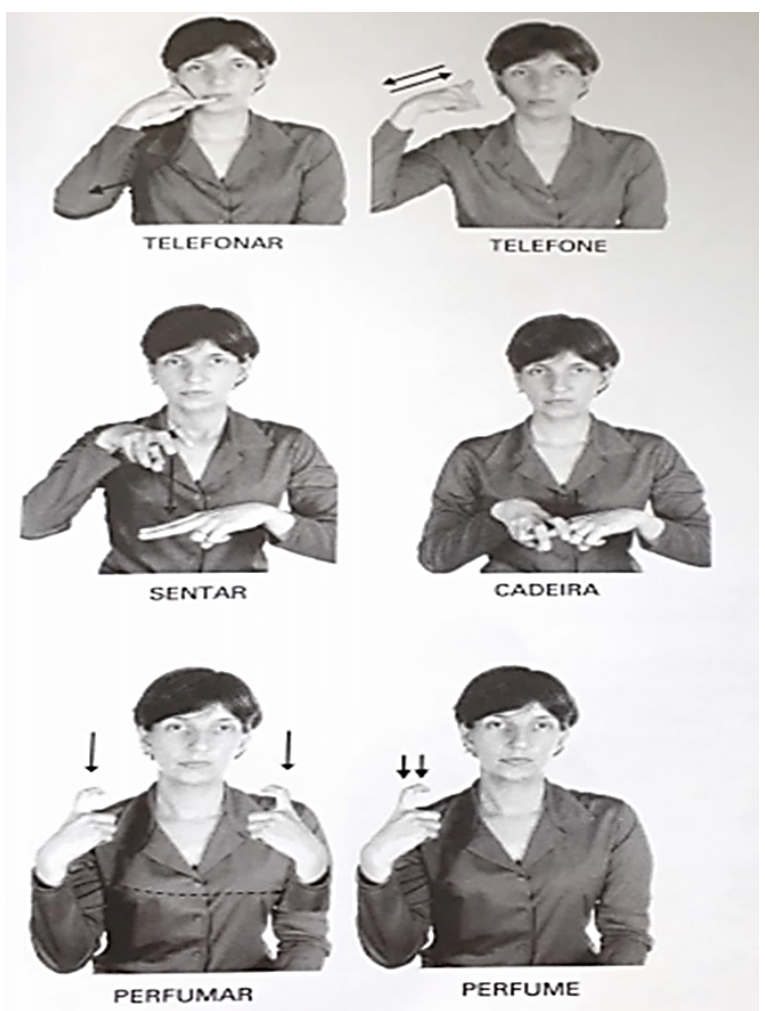

Fonte: Quadros e Karnopp (2004, p.97)

Dentre as discordâncias sobre a generalização morfológica categorizadora de $\mathrm{N}$ e $\mathrm{V}$, por meio da diferenciação de movimento em Libras, destacamos a pesquisa de doutorado de Pizzio (2011). $\mathrm{Na}$ tentativa de encontrar critérios para verificar essa suposta diferença entre N e V em Libras, Pizzio (2011) selecionou 25 pares de N e $\mathrm{V}$ e, com base em testes por ela realizados, observou que: 
Os resultados obtidos mostram que há bastante variação na produção dos indivíduos. Nem sempre foi observado o padrão esperado para a produção dos nomes e verbos, principalmente para aqueles pares que apresentam ou um movimento circular do sinal ou um movimento alternado de mãos e braços para realizar o sinal. Muitas vezes, os indivíduos não diferenciavam na sua produção o nome e o verbo, produzindo o mesmo sinal para ambos os casos (p. 227).

A autora asseverou que a variação de movimento adotado por Supalla e Newport (1978) para a ASL não era totalmente aplicável a Libras, uma vez que seus informantes não se apercebiam da distinção entre as duas categorias, produzindo exatamente o mesmo sinal para ambos os casos, ou se valia de outras estratégias para diferenciar essas categorias, como a realização de sinais compostos, principalmente para produzir nomes. A pesquisadora, portanto, conclui que:

Foi constatado que não é possível fazer a generalização de Supalla e Newport (1978) para os dados da Libras, pois nem todos os pares preenchem os requisitos de movimento longo e único para o verbo e movimento curto e reduplicado para o nome. Muitas vezes, essa impossibilidade ocorreu devido a restrições de formação do próprio sinal, quando não é possível produzir um movimento único e longo em virtude do movimento circular e do movimento alternado próprios de alguns verbos e nomes (PIZZIO, 2011, p. 225).

\section{Quanto à existência ou não em Libras de marca morfofonológica para as categorias nome e verbo}

Nesta seção, discutiremos os resultados sobre a forma articulatória e a ocorrência ou não de marca categorial morfológica nos 25 pares de $\mathrm{N}$ e $\mathrm{V}$, dos dados de cada informante, nos grupos de 
aquisição: SALI, SALPI, OFL. Para essa análise, tomamos a estrutura de base MLMov, proposta por Lessa-de-Oliveira $(2012,2019)$, como fundamento para a observação de traços e segmentos fonológicos que pudessem estar representando manifestações morfológicas categoriais.

No gráfico 1, podemos visualizar o percentual de articulação realizado pelos informantes dentro de seus respectivos grupos de aquisição. Do ponto de vista quantitativo, os dados apresentam o que mostra o gráfico a seguir:

\section{Gráfico 1: Articulação idêntica dos pares N e V por informante}

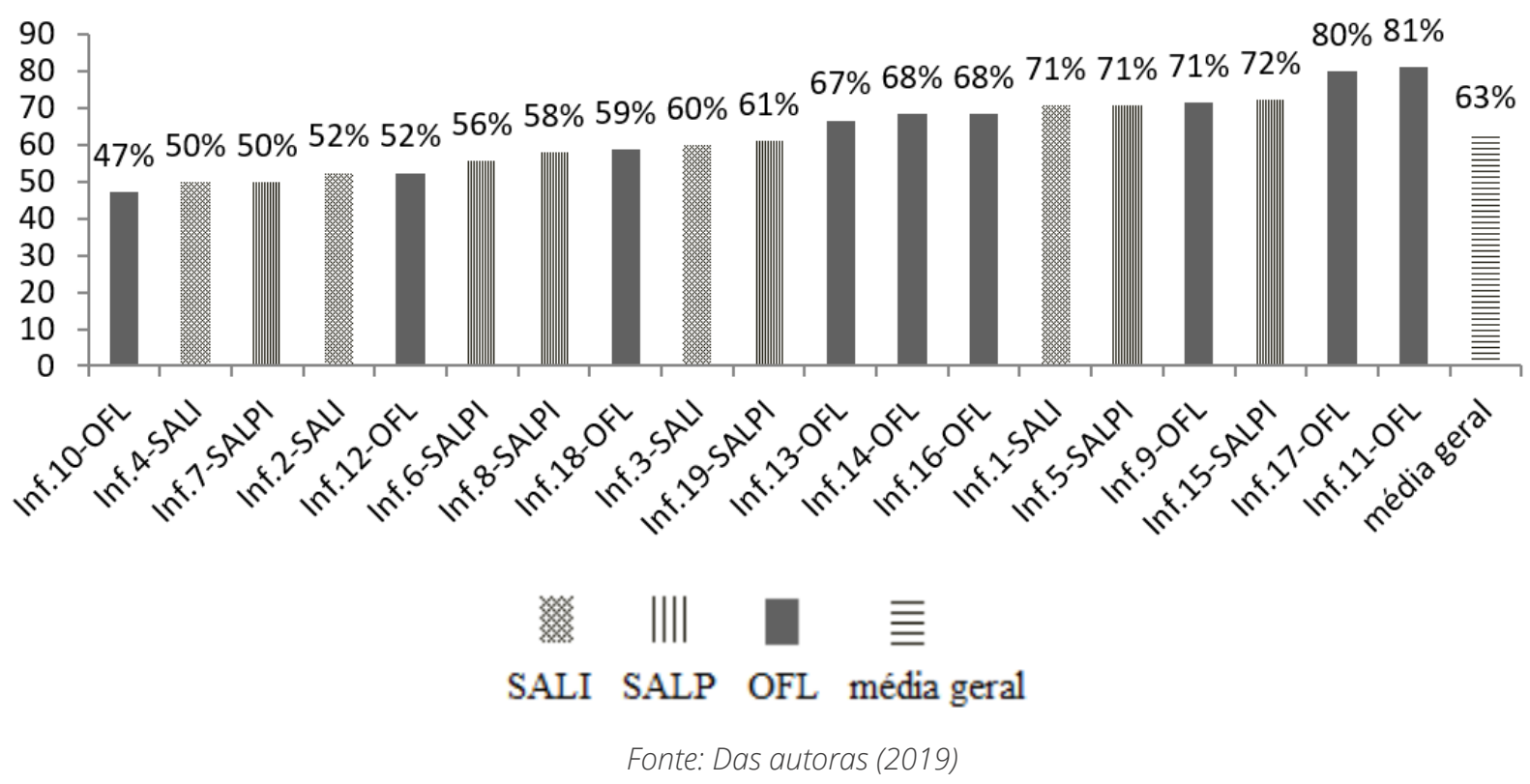

No tocante ao comportamento de cada informante, quanto à realização de sinais articulados de forma idêntica nas posições sintáticas $\mathrm{N}$ e $\mathrm{V}$, esse gráfico revela percentuais de formas idênticas para N e V, que vão de $47 \%$ a $81 \%$, evidenciando uma característica mais própria de L2 que de L1, nos três grupos, ligeiramente mais acentuada no grupo OFL, no qual encontramos o menor e o maior percentual. Olhando estatisticamente, temos um percentual médio de $63 \%$, que está bem próximo da mediana, que é $61 \%$. Verificamos que dois terços dos ouvintes estão acima da mediana, 
enquanto dois terços dos surdos encontram-se abaixo desta. Isso mostra que o padrão 'forma idêntica de $\mathrm{N}$ e $\mathrm{V}$ na realização do mesmo informante' é um pouco mais acentuado entre os ouvintes. Já entre os dois grupos de surdos, SALI e SALPI, cuja mediana é $59 \%$, observamos que temos exatamente a metade de cada grupo acima e abaixo desta. E, com relação à moda, esse aspecto 'forma idêntica de $\mathrm{N}$ e $\mathrm{V}$ na realização do mesmo informante' apresenta uma frequência de $71 \%$, tendo esse percentual ocorrido nos três grupos. Assim, os resultados indicam um comportamento bastante similar entre os três grupos, no tocante à ocorrência de formas idênticas para $\mathrm{N}$ e $\mathrm{V}$ realizadas pelo mesmo informante.

Olhando agora para cada sinal, verificando o percentual de ocorrências com forma articulatória idêntica para $\mathrm{N}$ e V, na produção do mesmo informante, temos o que se apresenta no gráfico 2.

\section{Gráfico 2: Sinais com articulação idêntica de $\mathrm{N}$ e V realizadas pelo mesmo informante}
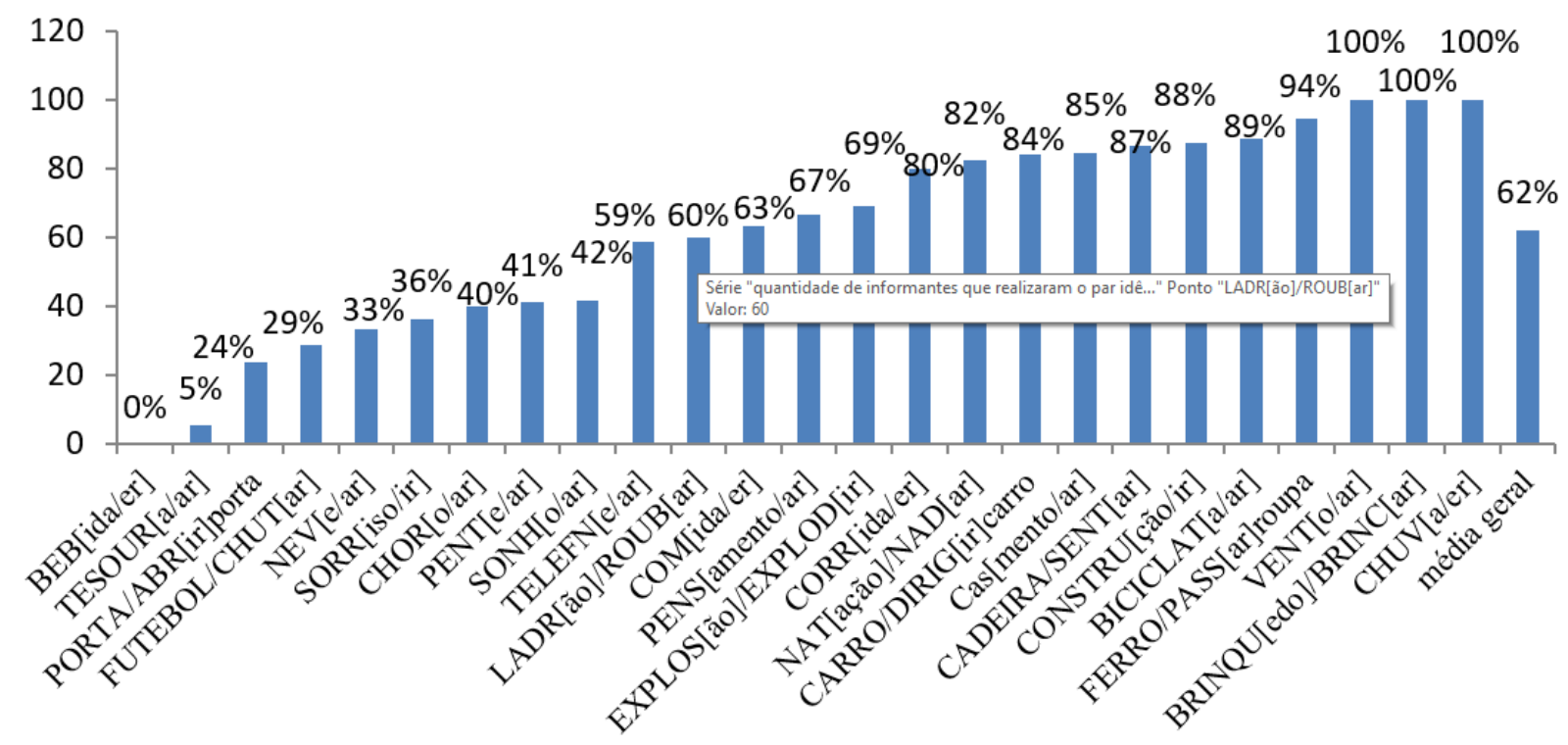

Fonte: as autoras (2019)

Observamos, no gráfico, que apenas o sinal BEB[ida/er] não apresentou ocorrência idêntica para $\mathrm{N}$ e $\mathrm{V}$ na produção do mesmo informante. TESOUR[a/ar] apresentou um percentual muito 
baixo, e mais 7 sinais apresentaram percentuais abaixo de $50 \%$. Os outros 16 sinais apresentaram percentuais acima de 50\%, com percentuais elevadíssimos, acima de $80 \%$, para quase metade dos sinais testados, 11 dos 25 . Observamos ainda que tanto a média (62\%) quanto a mediana (67\%) também estão acima dos 50\% e a moda é $100 \%$. Ou seja, chegamos a resultados que mostram que a ocorrência de 'forma idêntica do sinal, realizada pelo mesmo informante, para $\mathrm{N}$ e para $\mathrm{V}$ é quantitativamente muito significante.

Verificamos também os percentuais de ocorrência de forma idêntica para $\mathrm{N}$ e para $\mathrm{V}$, realizadas pelo mesmo informante ou por informantes diferentes. O resultado se apresenta no gráfico 3.

\section{Gráfico 3: Sinais com articulação idêntica de $\mathrm{N}$ e $\mathrm{V}$ realizados pelo mesmo informante ou por informantes diferentes}

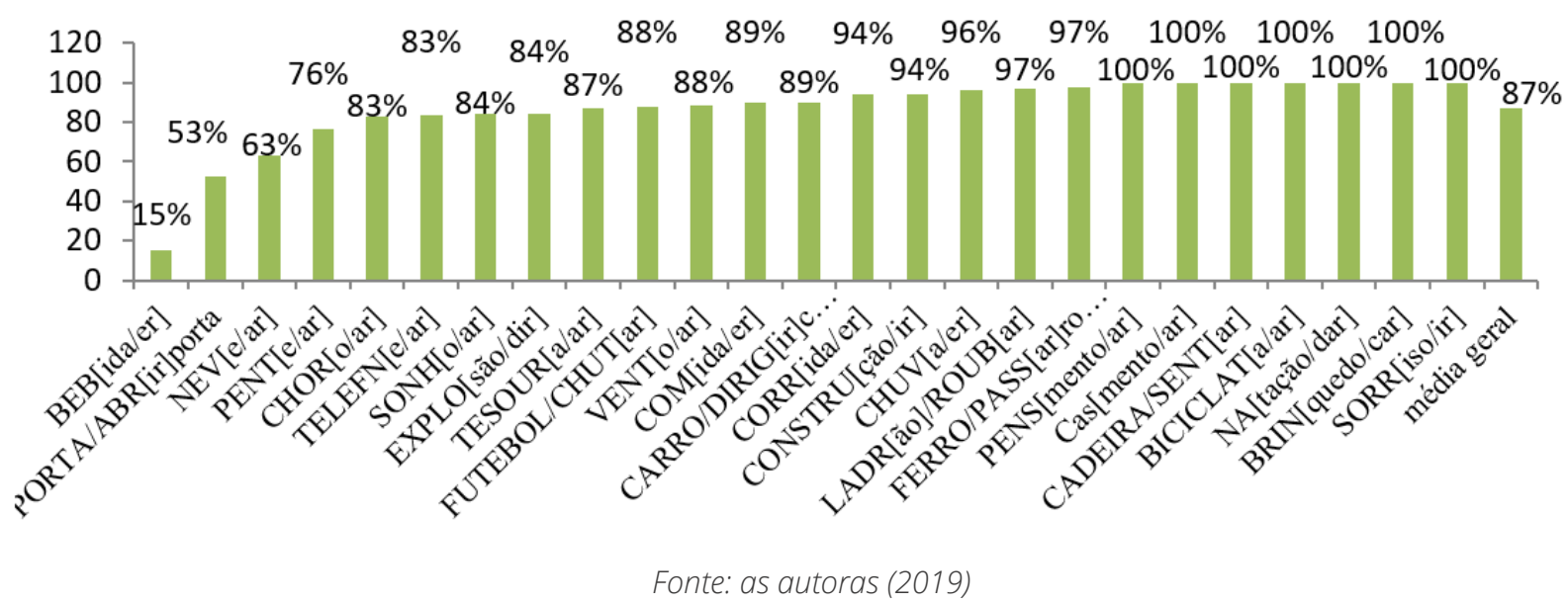

Vemos, no gráfico 3, que todos os sinais testados apresentaram ocorrência de forma articulatória idêntica em posição sintática de $\mathrm{N}$ e de $\mathrm{V}$, até mesmo BEB[ida/er], com ocorrências de $15 \%$. Os outros 24 pares de sinais testados apresentaram ocorrências acima de $50 \%$, sendo a média $87 \%$, a mediana $89 \%$ e a moda $100 \%$, percentual que ocorreu para 7 dos 25 pares. Ou seja, o que esses dados quantitativos estão mostrando é que, em Libras, de fato realiza-se a mesma forma articulatória do sinal em posições sintáticas nominais e verbais da frase. Se a mesma forma de alguns 
sinais não é observada na produção do mesmo falante como $\mathrm{N}$ e como $\mathrm{V}$, observamos essa forma na produção de outro falante no elemento oposto do par, em percentual elevadíssimo para quase todos os sinais testados.

Por outro lado, os dados também mostraram a presença de variação na forma articulatória de quase todos os sinais. Ainda que essa variação não represente marca categorial, é importante observá-las. No quadro a seguir apresentamos descrição de parte dessas variações, pois o presente artigo não comporta a descrição de todas as variações encontradas nos corpora.

\section{Quadro 2: Exemplos de variações encontradas nos pares testados}

\begin{tabular}{|c|}
\hline CONSTRU[ção/ir] \\
\hline 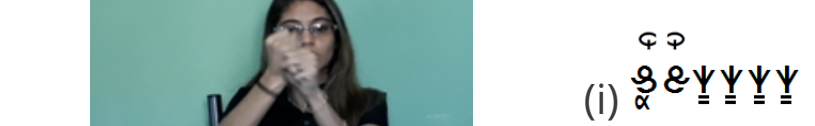 \\
\hline $\begin{array}{l}\text { Esse sinal apresentou-se de duas formas real } \\
\text { figuração das duas mãos em esse, no eixo ar } \\
\text { mão principal retilíneo brevíssimo para trás, ex } \\
\text { duas mãos em bê, no eixo medial/palma para } \\
\text { trás, alternado entre as duas mãos (ou, mais } \\
\text { retilíneo das duas mãos para cima), exemplc } \\
\text { ocorrência de compostos, quando o informa } \\
\text { temente (i) e (ii), tanto para N como para V. } \\
\text { realizar uma ação construída } 6 \text { (passar massa, } \\
\text { motivada pela imagem do teste. }\end{array}$ \\
\hline
\end{tabular}

6 Uma espécie de representação da ação que é construída pelo narrador. (cf. McCleary e Viotti, 2011). 


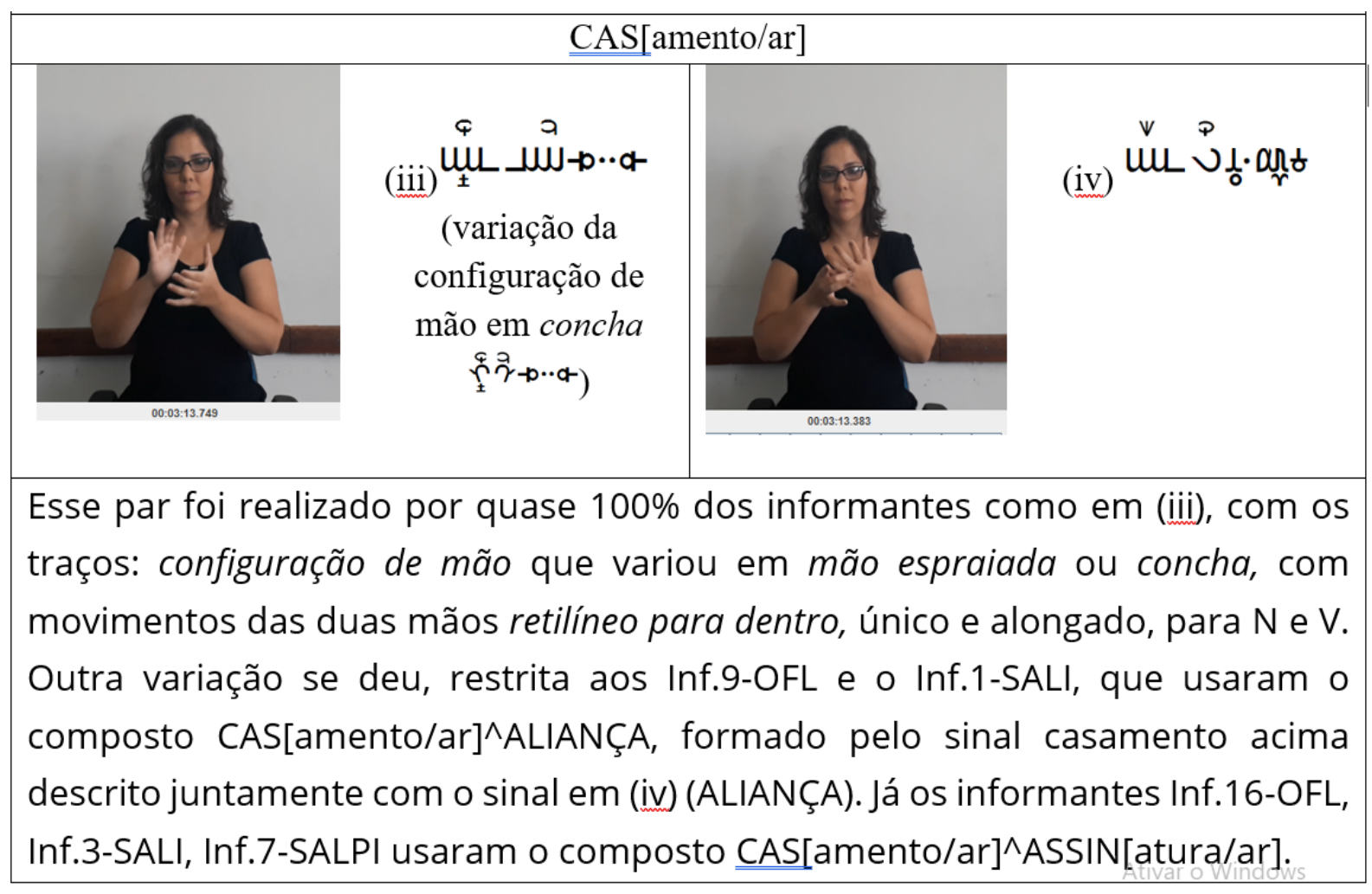

\begin{tabular}{|c|}
\hline TELEFON[e/ar]a \\
\hline 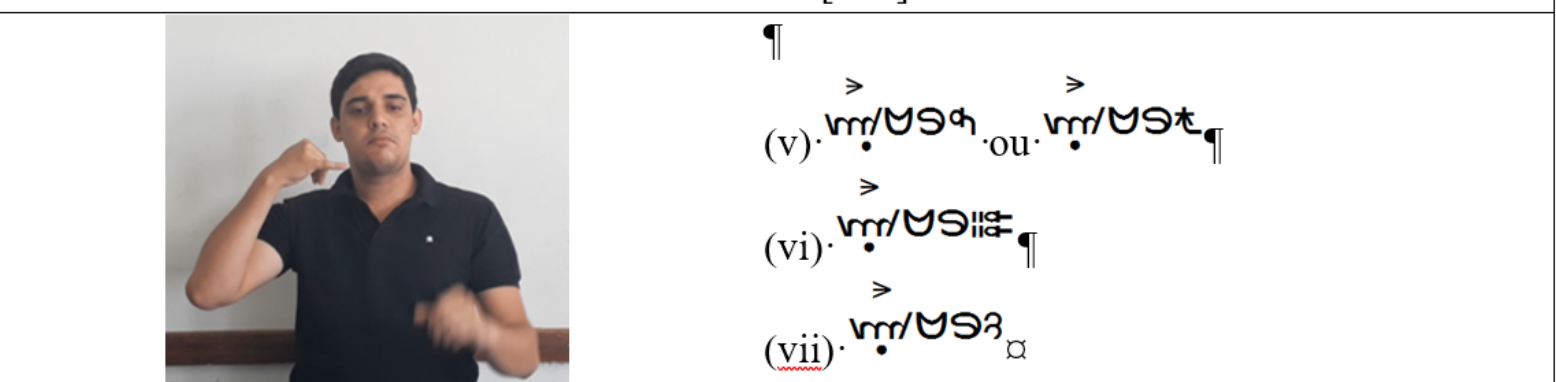 \\
\hline 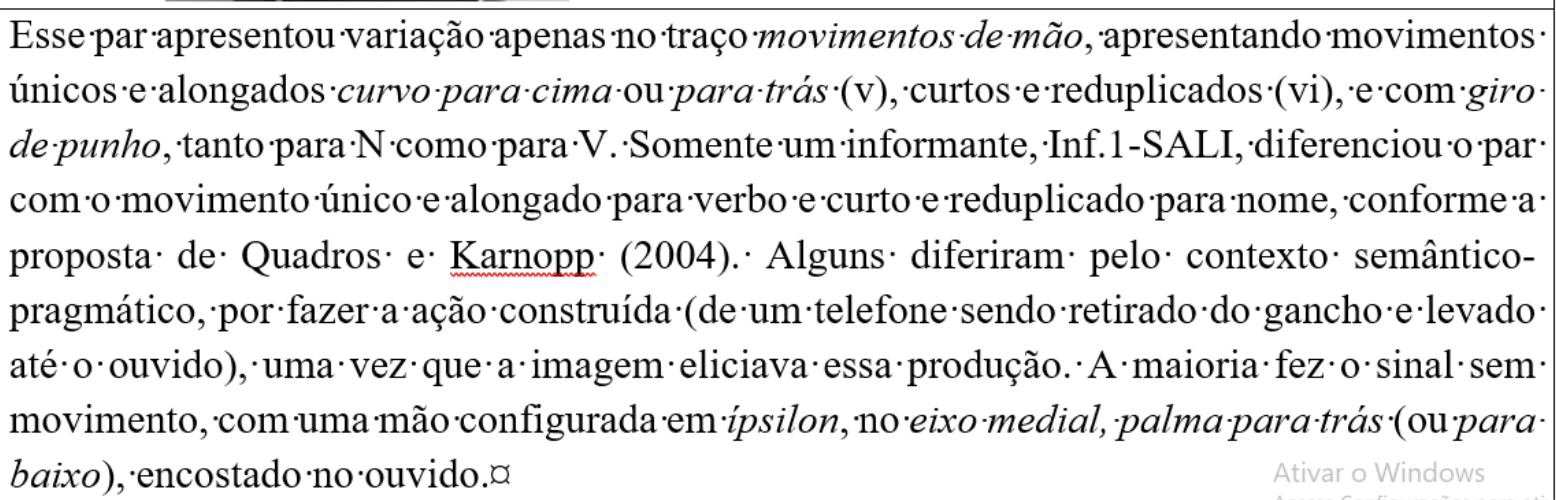 \\
\hline
\end{tabular}


Em resumo, a variação observada caracteriza-se como segue:

(A) Decorrem da variação de alguns traços, como nos exemplos (v), (vi), (vii) do sinal TELEFON[e/ar], nos exemplos (viii) e (ix) do sinal LADR[ão]/ROUB[ar] e dos exemplos (x), (xi), (xii) e (xiii) do sinal PORTA/ABRIRporta.

(B) São ocasionadas pela ocorrência de mais de um item lexical referentes a um mesmo conteúdo semântico, como CONSTRU[ção/ir] em (i) e (ii); FUTEBOL/CHUT[ar] em (xiv), (xv), (xvi) e (xvii). BEB[ida/er] tanto apresentou variação de item lexical quanto de alguns traços.

(C) Podem fazer composição com outro sinal, como CONSTRU[ção/ir], que apresentou também as formas (i) e (ii) juntas; CAS[amento/ar], cujo sinal convencional foi também empregado junto com o sinal ALIANÇA; e BEB[ida /er], que se associou ao sinal VÁRIOS.

(D) Decorre da alternância entre ocorrência ou não de autossaturação do verbo, isto é, incorporando ou não o objeto, como o sinal PORTA/ABRIRporta.

\section{Identificando nomes e verbos em estruturas sintáti- cas da Libras}

Consideramos que, para a observação de ocorrência ou não de variação no movimento ou de outro tipo de marcação de categorização, faz-se necessário, primeiramente, submeter os sinais obtidos no teste de eliciação ao critério sintático. Ou seja, analisando, nos dados de produção, a estrutura sintática em que se encontram os sinais dos pares investigados, temos condições mais seguras de estarmos de fato lidando com sinais $\mathrm{N}$ ou V. Assim, como procedimento metodológico, antes da análise morfofonológica apresentada na seção anterior, submetemos as frases produzidas pelos informantes a um escrutínio sintático. Por outro lado, essa análise sintática dos dados também serviu para demostrar que, se 
não é morfofonologicamente que as categorias gramaticais $\mathrm{N}$ e $\mathrm{V}$ são marcadas em Libras, o mecanismo de estabelecimento dessas categorias só pode ser sintático.

A fim de realizar uma investigação sintática dos dados livre de interferências da estrutura gramatical do português, procuramos analisar o segmento frásico produzido, como já mencionado, olhando diretamente para a sinalização, sem recorrer a glosas, procurando primeiramente os núcleos predicadores e seus argumentos, para definir, a partir das possíveis estruturas argumentais encontradas, o eixo oracional verbal, isto é, o sintagma verbal, VP (Verbal Phrase), e, consequentemente, os sintagmas nominais, ocupando as posições de argumento ou de predicador nominal.

Dessa forma, a análise ocorreu como se expõe a seguir. Por exemplo, verificando que o sinal que apresenta a forma articula-

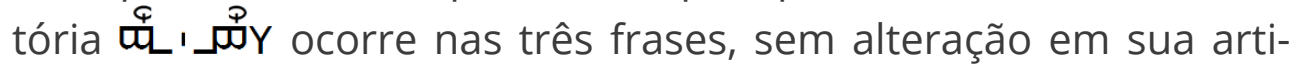
culação, procuramos analisar qual é a posição sintática de cada ocorrência.

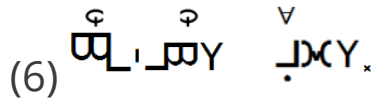

$\varnothing$ CORR[-] VENC[-] (INF6-GT)

'Venceram a corrida.' (ou 'Venci a corrida.' ou 'vitória da corrida')

(7)

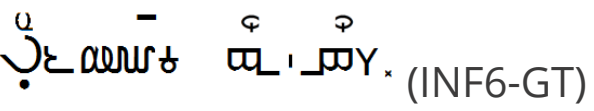

HOMEM CORR[-]

'O homem corre.' (ou 'corrida do homem')

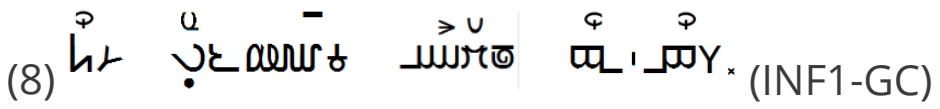

EST[-] HOMEM GOST[-] CORR[-]

'Este homem gosta de correr.' ou 'Este homem gosta de corrida.' 


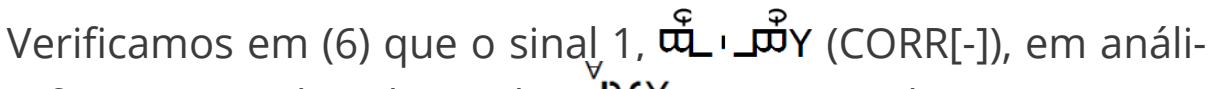

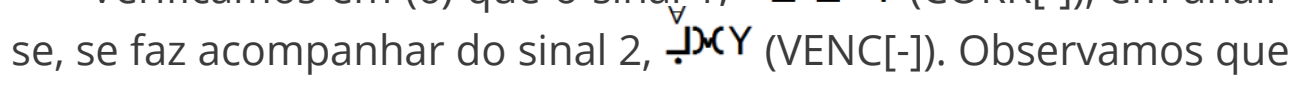
o sinal 2 pode ter: se for verbo, uma estrutura argumental que seleciona um argumento interno e um externo; se for nome, uma estrutura de um argumento interno. Nesse contexto argumental, o sinal 1, selecionado como argumento interno, será $\mathrm{N}$, seja na interpretação do sinal 2 como verbo 'Venci a corrida.' ou 'Venceram a corrida.', seja na interpretação desse sinal como nome 'vitória da corrida'. Como o teste eliciou a produção de frases, as interpretações em que temos o sinal 2 como verbo é que atendem a esse critério, pois a frase precisa de um eixo verbal. O sinal em análise é, portanto, da categoria N.

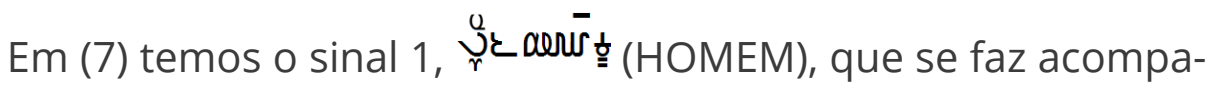
nhar do nosso sinal em análise, agora sinal 2. Da mesma maneira que fizemos com o exemplo anterior, observamos que o sinal 2 pode ter uma estrutura argumental que seleciona um argumento apenas, seja como nome ou como verbo. Assim, o sinal 1 é selecionado como argumento do sinal 2. Temos, então, a possibilidade de interpretar que o dado é 'o homem corre', se o sinal 2 for verbo, e o 'a corrida do homem', se o sinal 2 for nome. Verificamos que não houve a produção de nenhum outro sinal nesse dado que pudesse selecionar 'a corrida do homem' como argumento, assumindo o eixo verbal da frase. A interpretação nesse caso é 'o homem corre'. O sinal em análise é, portanto, da categoria V.

Já em (8), analisando o sinal $\mu^{u}$ r( (GOST[-]) como verbo que

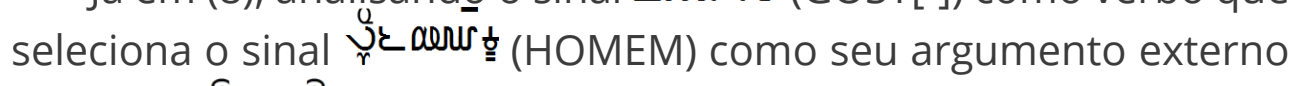

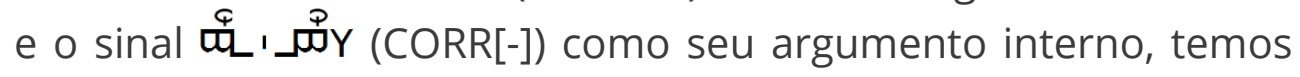
duas possibilidades para CORR[-], nessa posição. Ele pode ser um verbo ou um nome: 'Este homem gosta de correr. ' ou 'Este homem gosta de corrida.' Nesse caso, não temos elementos sintáticos para definir a categoria. Avaliando alternativamente o contexto semântico-pragmático, verificamos que CORRIDA $(\mathrm{N})$ remete ao evento realizado por pessoas de modo geral, e o contexto pragmático se refere ao fato de o homem da figura do teste gostar do ato de CORRER realizado por ele (na figura do teste aparece um homem 
correndo para o trabalho). Assim, a interpretação mais coerente desse sinal, nesse dado, é 'Este homem gosta de correr. ', isto é, trata-se de um verbo.

(9)

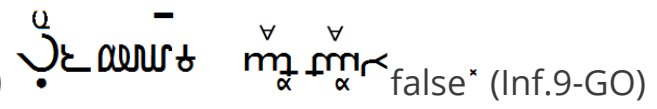

HOMEM PORTA/ABR[ir]porta

'O homem abriu a porta.'

(10)

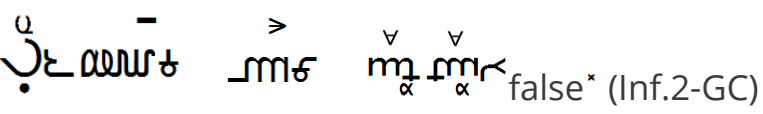

HOMEM CHEG[-] PORTA/ABR[ir]porta

'O homem chegou à porta.'

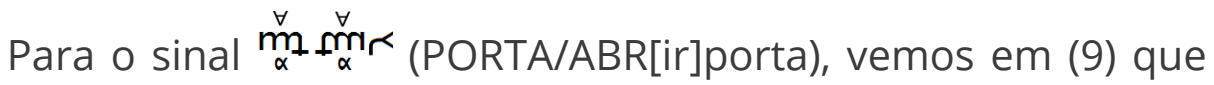
este está ocupando a posição de eixo verbal da oração, selecionando HOMEM como argumento externo, uma vez que o sinal HOMEM, por sua natureza semântica, não ocuparia função verbal

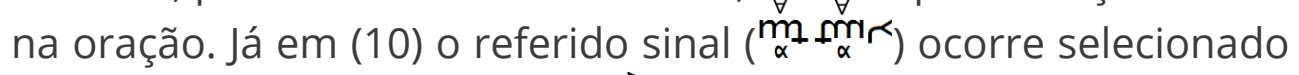
como argumento interno de $\stackrel{\vec{m}}{\vec{f}}$ (CHEG[-])7, com papel de Alvo. Temos aqui um caso inequívoco da categoria $N$ para o sinal ${\underset{\alpha}{\forall}}_{\substack{\forall \\ m_{\alpha}}}^{\forall}$ analisado, pois este será sempre um N como argumento interno,

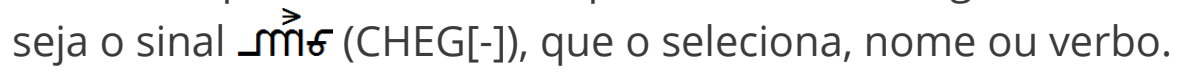

Uma observação interessante sobre esse sinal é que, nos dois exemplos, isto é, como $\mathrm{V}$ ou como $\mathrm{N}$, o movimento realizado ( $\boldsymbol{\sim}$ curvo transversal para frente) é uma variação do movimento que

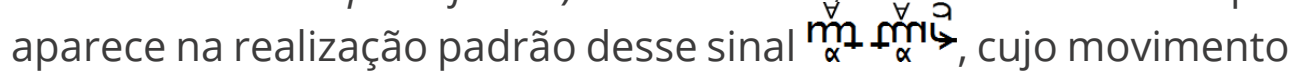
é curvo transversal para trás, $\mathbf{\$}$. Isso se deu em função das figuras apresentadas no teste de eliciação, que apresentavam, nos dois casos, alguém do lado de fora da porta batendo à porta, numa figura, e abrindo-a de fora para dentro, na outra. Isso reforça a

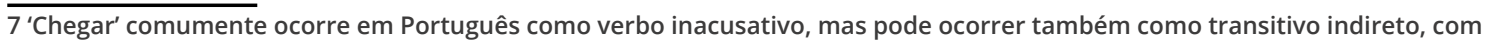
o sentido de 'alcançar'. 
observação de que não há em padrões de variação de movimento marca categorial, mas motivação pragmática.

Vemos, dessa forma, que a categorização de $\mathrm{N}$ e $\mathrm{V}$ em Libras depende da posição sintática ocupada pelo sinal, ou seja, independentemente da sua forma morfofonológica, os falantes da Libras identificam a categoria do sinal com base na posição sintática que esse ocupa na frase, se uma posição verbal, como núcleo do VP,

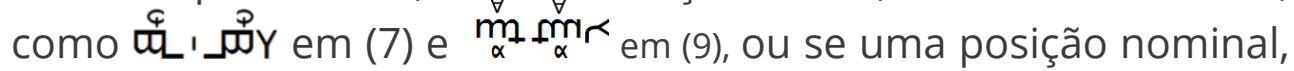
como argumento selecionado por um predicador, vindo a ocupar a posição sintática de sujeito ou complemento, como ⿷匚⿱

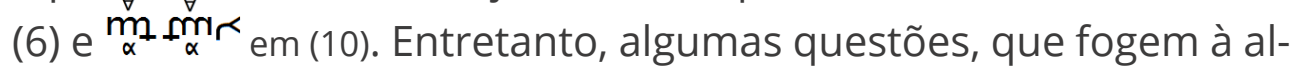
çada do presente trabalho, ficam em aberto para investigações fu-

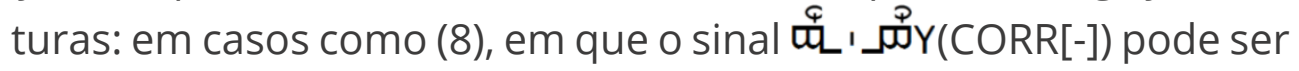
interpretado como $\mathrm{N}$ ou $\mathrm{V}$, sem que o valor de verdade da frase se altere, há para esse sistema gramatical a necessidade de especificação da categoria gramatical? Como essa especificação acontece?

\section{Conclusão}

Os resultados deste estudo apresentam evidência de que a distinção categorial em Libras não se dá de forma morfológica, mas apenas de forma sintática, uma vez que não foi verificado em nenhum dos 25 pares $\mathrm{N}$ e $\mathrm{V}$ de sinais testados nenhum traço morfofonológico responsável por distinção categorial. Verificamos ocorrências da mesma forma para $\mathrm{N}$ e $\mathrm{V}$ com média de $87 \%$ e a moda de $100 \%$, isto é, esse foi o percentual mais recorrente, encontrado em 7 dos 25 pares $\mathrm{N}$ e V.

Observamos indivíduos dos três grupos, SALI, SALPI e OFL, distribuídos entre os percentuais $47 \%$ a $81 \%$ de ocorrência idêntica para $\mathrm{N}$ e $\mathrm{V}$, com tendência ligeiramente maior entre os ouvintes do que entre surdos. Dois terços dos ouvintes ficaram acima da mediana, que foi de $61 \%$, enquanto que dois terços dos surdos ficaram abaixo. Esses resultados revelam que, independentemente do período de aquisição, os falantes de Libras surdos, e também os ouvintes, não fazem diferenciação morfofonológica das catego- 
rias $\mathrm{N}$ e V. E, quanto às variações localizadas, os dados não revelaram que a motivação para essa distinção seja a categorização.

Diante do exposto, concluímos que a categorização de itens lexicais em Libras se dá de forma estrutural, definida dentro do contexto sintático, e não de forma morfofonológica.

\title{
8 Referências Bibliográficas
}

\author{
CHOMSKY, Noam. Syntactic Structures. Berlin: Mouton de \\ Gruyter,1957.
}

CHOMSKY, Noam. Linguagem e mente. Brasília: Universidade de Brasília, 1998.

KATO, Mary. A gramática do letrado: questões para a teoria gramatical. In: MARQUES, Maria Aldina. et al. Ciências da linguagem: trinta anos de investigação e ensino. Braga: Centro de Est. Humanísticos, Universidade do Minho, 2005. 131- 145.

KENEDY, Eduardo. Curso básico de linguística gerativa. São Paulo: Contexto, 2016.

LENNEBERG, Eric. Biological Foundation of Language. New York: Wiley, 1967.

LESSA-DE-OLIVEIRA, Adriana S. C. Libras escrita: o desafio de representar uma língua tridimensional por um sistema de escrita linear. ReVEL, Brasil, v. 10, n. 19, 2012.

LESSA-DE-OLIVEIRA, Adriana S. C. Componentes articulatórios da Libras e a escrita SEL. Estudos da Língua(gem), Vitória da Conquista, v. 17, n. 2, p. 103-122, abr-jun de 2019.

MARINHO, Margot Latt. Língua de Sinais Brasileira: proposta de análise articulatória com base no banco de dados LSB-DF. 2014. 231f. Tese (Doutorado em Linguística) - Universidade de Brasília - Brasília, 2014. McCLEARY, Leland \& VIOTTI, Evani. Língua e gesto em línguas sinalizadas. In: Veredas on line, Juiz de Fora, 2011, p. 289-304. 
MIOTO, Carlos. et al. Novo Manual de Sintaxe. São Paulo: Contexto, 2016.

PIZZIO, Aline. A tipologia linguística e a língua de sinais brasileira: elementos que distinguem nomes de verbos. 2011. 237f. Tese (Doutorado em Linguística) pela Universidade Federal de Santa Catarina - UFSC, Florianópolis, 2011.

QUADROS, Ronice; KARNOPP, Lodenir Becker. Língua de sinais brasileira: estudos linguísticos. Porto Alegre: Artmed, 2004.

STOKOE, William. A dictionary of American Sign Language on linguistic principles. Silver Spring. Disponível em: https://adams.marmot. org/Record/.b17461169. Acesso em: 16 set. 2017.

SUPALLA, Ted; NEWPORT, Elis. How many seats in a chair? The derivation of nouns and verbs in american sign language. Disponível em: https:// www.researchgate.net/publication/313223392_Howmany_seats_in_a_ chair_The_derivation of nouns and verbs in American Sign Language. Acesso em: 20 jun. 2018. 